\title{
Research on Locating Model of Heavy Metal Pollutants Source Based on SFPI Method and 2D Convection-Diffusion Equation
}

\author{
Yi-Jian Liu ${ }^{1,2} \& \mathrm{Zi}-Y u \mathrm{Li}^{1,3}$ \\ ${ }^{1}$ Innovation Practice Base of Mathematical Modeling, Electrical and Information College of Jinan University, \\ Zhuhai, China \\ ${ }^{2}$ Electronic Information Science and Technology, Electrical and Information College of Jinan University, \\ Zhuhai, China \\ ${ }^{3}$ Finance Department of International Business School, Jinan University, Zhuhai, China. \\ Correspondence: Zi-Yu Li, Finance Department of International Business School, Jinan University, Qianshan \\ Road 206\#, Zhuhai City, Guangdong Province, Post No.519070, China. E-mail: 693903484@qq.com
}

Received: May 11, 2017

doi:10.5539/enrr.v7n2p68
Accepted: May 24, 2017

URL: https://doi.org/10.5539/enrr.v7n2p68

\begin{abstract}
As an important field in environmental science, the research on the locating issue of heavy metals pollutants source has increasingly attracted attention of scholars and society. In order to locate the pollutants source, we should firstly figure out the spatial distribution of heavy metals pollutants and pollution degree of different subareas in a limited area. Based on the datasheets from CUMCM 2011, we obtain the spatial distribution figures of heavy metals on MATLAB platform. Then, we introduce SFPI method to build an evaluation model of pollution degree in different subareas, with analyzing of the result of which, we can approximately conclude that the location of heavy metals pollutants source may be located in Industrial Area and Traffic Area. Further analyzing, to position the pollutants source more precisely, we introduce 2D convection-diffusion equation to describe the pollutant pathway of heavy metals, solve the equation with FDM algorithm on Maple platform, and obtain the propagation function of heavy metals concentration. Finally, we furtherly modify the propagation function and then figure out the precise coordinates of the pollution source and the corresponding subareas.
\end{abstract}

Keywords: Heavy Metals Pollutants, Positioning Model, SFPI Method, 2D convection-diffusion equation

\section{Introduction}

In today's society, with the development of urbanization, growing population and increasingly serious environment problem in the city, heavy metal pollution is a typical problem in the field of researching pollution in the environmental science. Nowadays, scholars in different countries begin to pay attention to heavy mental pollution including researches on the spreading route of heavy metal pollutants, the locating model of heavy metal pollutants and sources as well as the evaluation model of the pollution level in different areas of the city. Therefore, the scholars in the field of environmental science shall deeply study on the pollution source localization of heavy metal pollutants. Only confirming the pollution sources can we solve the problem of environmental pollution successfully.

Regarding series problems of heavy metal pollution, many scholars, in the field of environmental science, have made vast researches on the evaluation methods of heavy metal pollution degree and determination of heavy metal pollution sources. In the relevant research on evaluation method of pollutant pollution degree, Lin mentioned in her master's thesis that there are many evaluation methods of heavy mental pollution index nowadays, including Nemerow index method, Igeo (Geo-accumulation index method) and PLI (Pollution Load Index), etc (Lin, 2009). The Nemerau index method is a pollution evaluation index proposed by Nemerow (1971), in his River Pollution Scientific Analysis, which includes SFPI and comprehensive index evaluation method. Meanwhile, Li mentioned in her literature, that the Nemerow index method not only takes the average level of factor into account, but also thinks about the maximum pollution index. Therefore, it is relatively objective science ( $\mathrm{Li}$, Wu, Zhang, \& Lyu, 2008). Igeo (Muller, 1969), proposed by Muller, a scientist at the Institute of Sediments in Germany Heideiberg University of Heidelberg, was widely used to evaluate the pollution degree of heavy metal pollution of sediments and other substances (Qi, 2006). In addition, PLI is a 
heavy mental pollution evaluation method by Tomlinson's research team. The index consists of various heavy metal components contained in the evaluation area, which can directly reflect heavy mental contribution to environmental pollution and the changing trend of heavy metal content in time and space. (Wang, Liu, Fang \& Yuan, 2013; Lin, 2009). On the other hand, in the research of heavy metal pollution source localization, Lin and others have summarized the method to determine the pollution source of heavy metal in soil, including cluster analysis, multivariate statistics and other methods(Lin, Zhao, Hu, \& Su, 2011) .By cluster analysis, the data object can be classified according to the common features. The research team of Ahmed, B. Y. M. and Alidi, S.A has made more research in this area. (Ahmed, 1997) (Alidi, 1994). Meanwhile, Yan-ping Lin also mentioned the advantages and limitations of multivariate statistics in this thesis. In his master's thesis, Qin mentioned the application of convection-diffusion equation in the simulation of the propagation path of heavy metal elements. Because the method is based on a large number of previous experimental studies on mathematical and physics, its accuracy are better (Qin, 2009).

In this paper, based on the city heavy metal pollution data of CUMCM 2011, we firstly selected SFPI method in the Nemerow index method as the basis of evaluation model related heavy metal pollution degree and then analyzed the heavy metal pollution in the city. Besides, in the following article, HME is short for heavy metal elements. Then, we introduce the 2D convection-diffusion equation and further modify to make it adapt to the practical problem. Finally, we solve the propagation function with different contents of heavy mental in MATLAB and Maple software platform, based on which, we get the coordinates of different heavy metal pollution sources corresponding different subareas.

\section{Spatial Distribution of Different HMEs in the Urban Area}

Based on the datasheets of HMEs provided by CUMCM 2011 and MATLAB software platform, we draw 3D spatial distribution figures of different HMEs in the urban area, where 3D coordinate points, $(x, y, z)$,represent the spatial location and different colors at $3 \mathrm{D}$ coordinate points represent different HMEs concentration. Owing to the limited length, our paper only gives the 3D spatial distribution figure of HME As, which is showed in Figure 1.

By analyzing the correlation between altitude and HMEs concentration, we found that the altitude of the spatial location is weakly related to the HMEs concentration. Therefore, under the condition of ignoring the altitude of spatial locations, that is the value of $z$. We draw 2D spatial distribution figures of different HMEs in the urban area on MATLAB software platform. The 2D spatial distribution figure of HME As is shown in the Figure 2(owing to the limited length, 2D spatial distribution figures of other HMEs are shown in Appendix A).

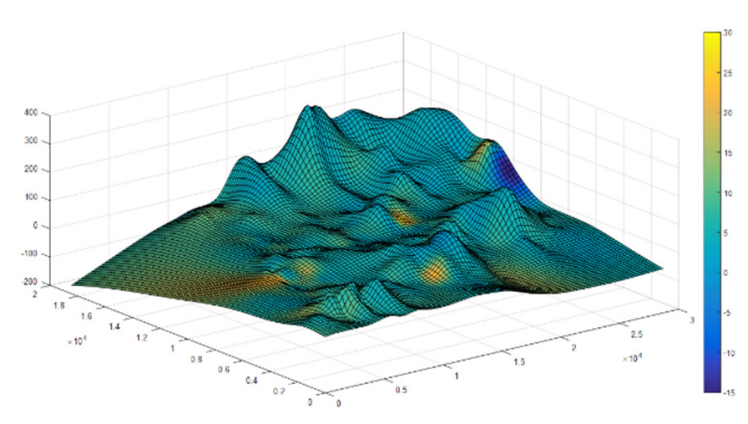

Figure 1. 3D Spatial Distribution of HME As

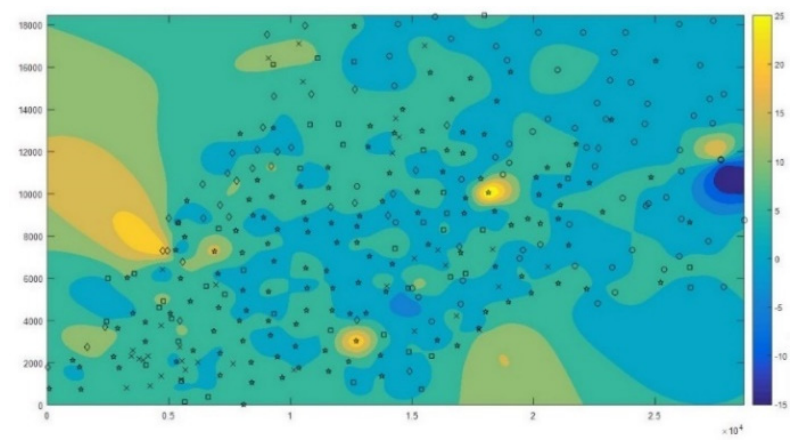

Figure 2. 2D Spatial Distribution of HME As

In Figure 2, 2D coordinate points, $(x, y)$, representing the spatial location and different colors at 2D coordinate points represent different HMEs concentration. By analyzing the Figure 2, we can safely conclude that different subareas of the urban area are all polluted by different HMEs, while the pollution vary from different subareas, among which the pollution in Traffic Area and Industrial Area is the most serious while Mountain Area and Park Area is completely opposite.

Analyzing 2D spatial distribution figures of other HMEs with the same method, we can obtain following conclusions:

(1) For As, Cr, Cd, Ni and $\mathrm{Zn}$, the pollution of Traffic Area rank first and Industrial Area rank second.

(2) For $\mathrm{Cu}$ and $\mathrm{Pb}$, the pollution of Industrial Area rank first and Traffic Area rank second.

(3) For Hg, the pollution of Industrial Area and Traffic Area are both serious. 


\section{Evaluation Model of HMEs' Pollution Degree in Different Subareas Based on SFPI Method}

\subsection{Introduction \& Improvement of SFPI Method}

There are various evaluation methods on HMEs' pollution degree, including SFPI (single factor pollution index method), Nemerow index method, PLI (Pollution Load Index) and Igeo (Geo-accumulation index method) etc.. By comparing different methods, we adopt SFP model to evaluate HMEs' pollution degree in different subareas, which is be more suitable proved by our former study.

The formula about SFPI method is shown as below.

$$
P_{i}=\frac{C_{i}}{S_{i}}
$$

where, $P_{i}$ is the environmental quality index of soil pollutant $i$;

$C_{i}$ is the measured value of soil pollutant $i, \mu \mathrm{g} \cdot \mathrm{kg}^{-1}$;

$S_{i}$ is the evaluation standard of soil pollutant $i, \mu g \cdot \mathrm{kg}^{-1}$.

Meanwhile, Table 1 shows the relationship between SFPI (single factor pollution index) and the pollution degree (Cheng, Cheng, Sang, Yu, Xi, \& Pi, 2013).

In Table 1, the pollution situation is more serious with the level increasing.

Based on the formula (1) shown above and the datasheets from CUMCM 2011, we can calculate SFPI in different subareas. Considering the small differences among the different levels of the evaluation criteria and the different quantities of sampling points in each subarea, we improve the SFPI method to evaluate the pollution degree. In this paper, we introduce pollution rate to represent the SFPI of different subareas. Table 2 shows the relationship between pollution rate and pollution degree.

\subsection{Evaluation Model of HMEs' Pollution Degree in Different Subareas}

Based on the improved SFPI method introduced above, we can firstly calculate the SFPI of HMEs at all sample points. Then, according to the relationship between SFPI and pollution degree, we can judge the pollution degree of all sampling points. Finally, we can calculate the percentage of sampling points with different pollution degree accounting for all sampling points, that is the pollution rate, with which we can figure out the corresponding pollution degree.

Therefore, we can calculate the pollution degree of different subareas. Owing to the limited length, we only show the pollution degree situations of Living Area as an example, while other subareas are shown in Appendix B.

Table 1. Relationship between SFPI \& Pollution Degree

\begin{tabular}{cccccc}
\hline$P_{i}$ & $<1$ & $1 \sim 2$ & $2 \sim 3$ & $3 \sim 5$ & $\geq 5$ \\
\hline Pollution Degree & I & II & III & IV & V \\
\hline
\end{tabular}

Table 2. Relationship between Pollution Rate \& Pollution Degree

\begin{tabular}{cccccc}
\hline Pollution Rate & $<20 \%$ & $20 \% \sim 30 \%$ & $30 \% \sim 50 \%$ & $50 \% \sim 70 \%$ & $\geq 70 \%$ \\
\hline Pollution Degree & I & II & III & IV & V \\
\hline
\end{tabular}

Table 3. Pollution Degree of Living Area

\begin{tabular}{|c|c|c|c|c|c|c|c|}
\hline \multirow{3}{*}{ HMEs } & \multicolumn{5}{|c|}{$P_{i}$} & \multirow{3}{*}{$\begin{array}{c}\text { Pollution } \\
\text { Rate }\end{array}$} & \multirow{3}{*}{$\begin{array}{r}\text { Pollution } \\
\text { Degree }\end{array}$} \\
\hline & $P_{i}<1$ & $1 \leq P_{i}<2$ & $2 \leq P_{i}<3$ & $3 \leq P_{i}<5$ & $P_{i} \geq 5$ & & \\
\hline & Percentage & Percentage & Percentage & Percentage & Percentage & & \\
\hline As & $11.36 \%$ & $56.82 \%$ & $27.27 \%$ & $4.55 \%$ & $0.00 \%$ & $31.82 \%$ & III \\
\hline $\mathrm{Cd}$ & $15.91 \%$ & $38.64 \%$ & $29.55 \%$ & $11.36 \%$ & $4.55 \%$ & $45.45 \%$ & III \\
\hline $\mathrm{Cr}$ & $9.09 \%$ & $70.45 \%$ & $11.36 \%$ & $4.55 \%$ & $4.55 \%$ & $20.45 \%$ & II \\
\hline $\mathrm{Cu}$ & $4.55 \%$ & $36.36 \%$ & $18.18 \%$ & $20.45 \%$ & $20.45 \%$ & $59.09 \%$ & IV \\
\hline $\mathrm{Hg}$ & $29.55 \%$ & $27.27 \%$ & $18.18 \%$ & $11.36 \%$ & $13.64 \%$ & $43.18 \%$ & III \\
\hline $\mathrm{Ni}$ & $15.91 \%$ & $70.45 \%$ & $13.64 \%$ & $0.00 \%$ & $0.00 \%$ & $13.64 \%$ & I \\
\hline $\mathrm{Pb}$ & $13.64 \%$ & $54.55 \%$ & $18.18 \%$ & $9.09 \%$ & $4.55 \%$ & $31.82 \%$ & III \\
\hline $\mathrm{Zn}$ & $11.36 \%$ & $45.45 \%$ & $13.64 \%$ & $20.45 \%$ & $9.09 \%$ & $43.18 \%$ & III \\
\hline
\end{tabular}


Further analyzing, we can obtain the pollution degree of different subareas. Table 4 shows the pollution degree of different subareas.

Table 4. Pollution Degree of Subareas

\begin{tabular}{ccccccccc}
\hline \multirow{2}{*}{ Subareas } & \multicolumn{10}{c}{ HMEs } \\
\cline { 2 - 8 } & $\mathrm{As}$ & $\mathrm{Cd}$ & $\mathrm{Cr}$ & $\mathrm{Cu}$ & $\mathrm{Hg}$ & $\mathrm{Ni}$ & $\mathrm{Pb}$ & $\mathrm{Zn}$ \\
\hline Living Area & III & III & II & IV & III & I & III & III \\
Industrial Area & III & IV & II & V & IV & II & IV & IV \\
Mountain Area & I & I & I & I & I & I & I & I \\
Traffic Area & I & IV & I & IV & III & I & III & IV \\
Park Area & II & III & I & III & III & I & II & II \\
\hline
\end{tabular}

Analyzing the table 4, we can safely draw following conclusions:

(1) Among 5 subareas of the urban, the Traffic Area and the Industrial Area is the most polluted subareas. Besides, the less polluted subareas are the Living Area and the Park Area. Meanwhile, the Mountain Area is the most environmentally friendly.

(2) Analyzing horizontally in Table 4, we can figure out that in the Living Area and the Industrial Area, the central HME pollution source are both $C u$, while in the Traffic Area, those are $C d, C u$ and $Z n$.Also, in the Park Area, those includes $\mathrm{Cd}, \mathrm{Cu}$ and $\mathrm{Hg}$.Fortunately, the Mountain Area is absolutely environmentally friendly.

(3) Analyzing vertically on Table 4, we can find that the pollution source of $\mathrm{As}$ and $\mathrm{Cr}$ have a great possibility to be located in Living Area or Industrial Area. What's more, the pollution source of $C d$ and $Z n$ are both probably located in Industrial Area or Traffic Area. Meanwhile, the pollution source of $\mathrm{Cu}, \mathrm{Hg}, \mathrm{Ni}$ and $\mathrm{Pb}$ are all probably located in Industrial Area.

After the analysis on Table 4, we can give a general conclusion about the locations of pollution source of different HMEs. Furtherly, we will build a locating model of the pollution source of HMEs as below.

\section{Locating Model of the Pollution Source of HMEs Based on 2D Convection-Diffusion Equation}

\subsection{Data Preprocessing}

Before building the locating model of the pollution source, we can easily find that the concentration of HMEs are related to the spatial location $(x, y, z)$.In order to simplify the analysis, we want to simplify the 3D spatial location to 2D. Based the datasheets from CUMCM 2011 and SPSS software platform, we exert standardized processing and correlation analysis to the concentration of HMEs and the value of $z$. The result is shown in Table 5 .

Table 5. Correlation Matrix of the Concentration of HMEs \& the Altitude $z$

\begin{tabular}{cccccccccc}
\hline & $A s$ & $C d$ & $C r$ & $H g$ & $N i$ & $P b$ & $Z n$ & $C u$ & $z$ \\
\hline$A s$ & 1.000 & & & & & & & & \\
$C d$ & 0.255 & 1.000 & & & & & & \\
$C r$ & 0.189 & 0.352 & 1.000 & & & & & \\
$H g$ & 0.064 & 0.265 & 0.103 & 1.000 & & & & \\
$N i$ & 0.317 & 0.329 & 0.716 & 0.103 & 1.000 & & & \\
$\mathrm{~Pb}$ & 0.290 & 0.660 & 0.383 & 0.298 & 0.307 & 1.000 & & \\
$\mathrm{Zn}$ & 0.247 & 0.431 & 0.424 & 0.196 & 0.436 & 0.494 & 1.000 & & \\
$\mathrm{Cu}$ & 0.160 & 0.397 & 0.532 & 0.417 & 0.495 & 0.520 & 0.387 & 1.000 & \\
$z$ & 0.289 & 0.248 & 0.152 & -0.084 & -0.163 & -0.235 & -0.178 & -0.138 & 1.000 \\
\hline
\end{tabular}

Table 5 is a correlation matrix of the concentration of HMEs and the value of $z$, the blanks of which represent zero. The datum in Table 5 represent the relative coefficient between the horizontal variables and vertical variables. Analyzing the datum of the last line in Table 5, we can obtain $r_{i j}$, the relative coefficients between different HMEs and $z$. When $r_{i j}>0$, it means there is a positive correlation between two variables while $r_{i j}<0$ means there is a negative correlation between two variables. What's more, if $\left|r_{i j}\right|>0.7$, it indicates that 
the relationship between two variables is a strong correlation while $\left|r_{i j}\right|<0.3$ indicates that the relationship between two variables is a weak correlation. Therefore, we can easily find that all of HMEs have weak correlations with $z$.Consequently, we can safely draw a conclusion that the concentration of HMEs have a little relationship with the altitude of spatial locations and we can only consider the relationship between 2D spatial location $(x, y)$ and the concentration of HMEs.

\subsection{Introduction of $2 D$ Convection-Diffusion Equation}

\subsubsection{Background \& Application of 2D Convection-Diffusion Equation}

2D convection-diffusion model, is mainly used to study the change laws of some physical quantities carried by fluid particles, such as the concentration of solutions in fluid. It has been widely used to study the relation between the dependent variable, pollutants concentration, and independent variables, time and spatial position. Furtherly, the model consists of 3 main parts, including convection process, diffusion process and the process of physical quantities decay or growth caused by some physical and chemical factors.

\subsubsection{D Convection-Diffusion Model}

Suppose a 2D convection-diffusion equation(Sun,2011)

$$
\varphi=\varphi(x, y, t)
$$

where, $\varphi$ is the pollutant concentration per unit volume fluid;

$(x, y)$ represents 2D spatial locations;

$t$ represents time.

Introduce a limited area $D$ with boundary $S$.We study on the solution of $\varphi=\varphi(x, y, t)$ in a limited area $D$ with boundary $S$. The following analysis is 3 main physical processes, including convection process, diffusion process and source-sink analysis.

\section{(1) Convection Process}

In convection process, what influence $\varphi$ in limited area $D$ consists of two aspects, including 2D spatial locations $(x, y)$ and time $t$.In limited area $D$, the change of the integral of $\varphi$ can be represented as formula (3).

$$
\frac{d}{d t} \iint_{D} \varphi d D=\iint_{D} \frac{\partial \varphi}{\partial t} d D+\int_{S} \varphi \overrightarrow{u_{n}} d S
$$

where, $\overrightarrow{u_{n}}=u \cdot \vec{n}, \overrightarrow{u_{n}}$ represents the normal vector of fluid velocity vector at boundary $S$.

With Green-Gauss formula $\int_{S} \varphi \overrightarrow{u_{n}} d S=\iint_{D} d i v(\varphi u) d D$, we can obtain formula (4).

$$
\frac{d}{d t} \iint_{D} \varphi d D=\iint_{D}\left[\frac{\partial \varphi}{\partial t}+\operatorname{div}(\varphi u)\right] d D
$$

\section{(2) Diffusion Process}

According to Fick Law, the diffusion velocity $q$ is positively related to the gradient of the concentration at the section $\varphi$.

where, $K$ is diffusion coefficient.

$$
q=-K \nabla \varphi
$$

Under the effect of diffusion and convection process, we can obtain formula (6).

$$
-\int_{S} \vec{n} q d S=\iint_{D} \operatorname{div}(K \nabla \varphi) d D
$$

(3) Source-Sink Analysis

Physical quantity $\varphi$ in the flow field will change because of the presence of source and $\operatorname{sink}$. Let $Q$ be distribution function. When $Q>0$, it means source while when $Q<0$, it means sink. Due to source and sink, we have $\Delta \varphi=\iint_{0} Q d D$.

According to the conservation law and the analysis on convection process, diffusion process and source-sink, we conclude as formula (7).

$$
\frac{\partial \varphi}{\partial t}+\varphi \operatorname{div}(u)=\operatorname{div}(K \nabla \varphi)+Q
$$

Formula (7) is 2D convection-diffusion equation. 
Without considering physical and chemical changes among heavy metal ions and the change of the quantity of pollutants in limited area $D$, we can simplify the formula (7):

$$
\frac{\partial \varphi}{\partial t}=\operatorname{div}(K \nabla \varphi)
$$

Furtherly analyzing the Formula (8), we have modified 2D convection-diffusion equation:

$$
K\left(\frac{\partial^{2} \varphi}{\partial x^{2}}+\frac{\partial^{2} \varphi}{\partial y^{2}}\right)-\frac{\partial \varphi}{\partial t}=0
$$

\subsection{Solution to 2D Convection - Diffusion Equation Based on FDM Algorithm}

Finite difference method (FDM) is a method for finding the numerical solution of partial differential equations. On the basis of the analysis in 4.2, the FDM's algorithm principle will be shown as follows.

\section{Step1 Divide the limited area}

Choose suitable steps $\Delta x, \Delta t$ and then, divide the limited area by two sets of lines parallel to the axis in the coordinate plane

$$
\begin{aligned}
& x_{i}=x_{0}+i \Delta x,(i=0,1,2 \cdots,) \\
& y_{i}=y_{0}+i \Delta y,(i=0,1,2 \cdots,) \\
& t_{n}=n \Delta t
\end{aligned}
$$

\section{Step2 Approximate substitution method}

Aiming at the objective equation,

$$
K\left(\frac{\partial^{2} \varphi}{\partial x^{2}}+\frac{\partial^{2} \varphi}{\partial y^{2}}\right)-\frac{\partial \varphi}{\partial t}=0
$$

When $(x, y, t)=\left(x_{i}, y_{i}, t_{n}\right)$, we can get

$$
K\left(\frac{\partial^{2} \varphi}{\partial x_{i}^{2}}+\frac{\partial^{2} \varphi}{\partial y_{i}^{2}}\right)-\frac{\partial \varphi}{\partial t_{n}}=0
$$

Time derivative is approximately replaced by first-order forward difference quotient:

$$
\frac{\partial \varphi}{\partial t} \approx \frac{\varphi_{i}^{n+1}-\varphi_{i}^{n}}{\Delta t}
$$

Spatial derivative is approximately replaced by second-order central difference quotient:

$$
\begin{aligned}
& \frac{\partial^{2} \varphi}{\partial x^{2}} \approx \frac{u_{i+1, j}-2 u_{i, j}+u_{i-1, j}}{(\Delta x)^{2}}+\mathrm{O}(\Delta x)^{2} \\
& \frac{\partial^{2} \varphi}{\partial y^{2}} \approx \frac{u_{i+1, j}-2 u_{i, j}+u_{i-1, j}}{(\Delta y)^{2}}+\mathrm{O}(\Delta y)^{2}
\end{aligned}
$$

Therefore, Formula (14) becomes:

\section{Step3 Difference equations}

$$
\mathrm{K}\left[\frac{u_{i+1, j}-2 u_{i, j}+u_{i-1, j}}{(\Delta x)^{2}}+\mathrm{O}(\Delta x)^{2}+\frac{u_{i+1, j}-2 u_{i, j}+u_{i-1, j}}{(\Delta y)^{2}}+\mathrm{O}(\Delta y)^{2}\right]-\frac{\varphi_{i}^{n+1}-\varphi_{i}^{n}}{\Delta t}=0
$$

On the basis of Step1 and Step2, we can obtain Formula (19):

$$
\left\{\begin{array}{l}
\mathrm{K}\left[\frac{u_{i+1, j}-2 u_{i, j}+u_{i-1, j}}{(\Delta x)^{2}}+\mathrm{O}(\Delta x)^{2}+\frac{u_{i+1, j}-2 u_{i, j}+u_{i-1, j}}{(\Delta y)^{2}}+\mathrm{O}(\Delta y)^{2}\right]-\frac{\varphi_{i}^{n+1}-\varphi_{i}^{n}}{\Delta t}=0 \\
\varphi^{0}=\varphi\left(x_{i}\right)
\end{array}\right.
$$

Based on the steps shown above, we use Maple software to solve the 2D convection - diffusion equation. The Formula (20) is the general solution to the 2D convection - diffusion equation.

$$
\varphi(x, y, t)=\left(c_{1} e^{\sqrt{c_{1} x}}+c_{2} e^{-\sqrt{c_{1} x}}\right)\left(c_{1} e^{\sqrt{c_{2} y}}+c_{2} e^{-\sqrt{c_{2} y}}\right) \mathrm{c}_{1} e^{-K\left(c_{1}+c_{2}\right) t}
$$

where, $c_{1}$ and $c_{2}$ are both constants; $K$ is diffusion coefficient. Consequently, Formula (20) is HMEs concentration propagation function. 


\subsection{Analysis on the Location of Pollutants Source Based on $\varphi(x, y, t)$}

\subsubsection{Introduction of the Modified $\varphi(x, y, t)$}

With the premise discussed above, that the quantity of pollutants is a constant, and the fact that the datasheets from CUMCM 2011 are all measured at a particular moment, we can suppose the next moment is $t_{1}$ and then the concentration of HMEs at the same spatial location can be represented as $\varphi_{1}=\Delta \varphi=\varphi(x, y, \Delta t)$. Therefore, the concentration of HMEs $\varphi$ is related to $\Delta t$, but not the time origin $t_{0}$.

Furtherly analyzing, we choose the moment when the original datum is measured as time origin, that is $t_{0}=0$.Consequently, we can simplify Formula (20) into Formula (21):

$$
\varphi(x, y, 0)=\left(c_{1} e^{\sqrt{c_{1}} x}+c_{2} e^{-\sqrt{c_{1}} x}\right)\left(c_{1} e^{\sqrt{c_{2}} y}+c_{2} e^{-\sqrt{c_{2}} y}\right) c_{1}
$$

That is,

$$
\varphi(x, y)=c_{1}\left(c_{1} e^{\sqrt{c_{1}} x}+c_{2} e^{-\sqrt{c_{1}} x}\right)\left(c_{1} e^{\sqrt{c_{2} y}}+c_{2} e^{-\sqrt{c_{2}} y}\right)
$$

4.4.2 Analysis on the Location of Pollutants Source Based on the Modified $\varphi(x, y, t)$

Consider the modified $\varphi(x, y, t)$

$$
\varphi(x, y)=c_{1}\left(c_{1} e^{\sqrt{c_{1}} x}+c_{2} e^{-\sqrt{c_{1}} x}\right)\left(c_{1} e^{\sqrt{c_{2} y}}+c_{2} e^{-\sqrt{c_{2}} y}\right)
$$

we can clearly find that constants $c_{1}$ and $c_{2}$ vary with different HMEs, which means that the 8 different HMEs in this paper is corresponding to 8 different concentration propagation functions $\varphi_{i}(x, y),(i=1,2, \cdots, 8)$ Therefore, before affirming the location of different HME pollutants, we firstly use ergodic cycle method to affirm different $\varphi_{i}(x, y)$ corresponding to different HMEs. Next, based on $\varphi_{i}(x, y)$ and 2D spatial distribution figures of HMEs shown above, we can calculate the maximum concentration location, which is the location of HMEs pollutants. On MATLAB software platform, we calculate all results which are all shown in Table 6 and Table 7.

Table 6. $\varphi_{i}(x, y)$ of HMEs

\begin{tabular}{cc}
\hline HMEs & $\varphi_{i}(x, y)$ \\
\hline As & $\varphi(x, y)=0.8 M\left(0.8 e^{\sqrt{0.8} x}+4.5 e^{-\sqrt{0.8} x}\right)\left(0.8 e^{\sqrt{4.5} y}+4.5 e^{-\sqrt{4.5} y}\right)$ \\
$C r$ & $\varphi(x, y)=2.1 M\left(2.1 e^{\sqrt{2.1} x}+e^{-\sqrt{2.1} x}\right)\left(0.8 e^{y}+e^{-y}\right)$ \\
$C u$ & $\varphi(x, y)=4 M\left(4 e^{2 x}+4 e^{-2 x}\right)\left(4 e^{2 y}+4 e^{-2 y}\right)$ \\
$H g$ & $\varphi(x, y)=10 M\left(10 e^{\sqrt{10} x}+15 e^{-\sqrt{10} x}\right)\left(10 e^{\sqrt{15} y}+15 e^{-\sqrt{15} y}\right)$ \\
$\mathrm{Ni}$ & $\varphi(x, y)=2 M\left(2 e^{\sqrt{2} x}+e^{-\sqrt{2} x}\right)\left(2 e^{y}+e^{y}\right)$ \\
$\mathrm{Pb}$ & $\varphi(x, y)=4.5 M\left(4.5 e^{\sqrt{4.5} x}+4 e^{-\sqrt{4.5} x}\right)\left(4 . e^{2 y}+4 e^{-2 y}\right)$ \\
$\mathrm{Zn}$ & $\varphi(x, y)=3.4 M\left(3.4 e^{\sqrt{3.4 x}}+4.2 e^{-\sqrt{3.4} x}\right)\left(3.4 e^{\sqrt{4.2} y}+4.2 e^{-\sqrt{4.2} y}\right)$
\end{tabular}

where, $M=e^{-K\left(\mathrm{c}^{(i)}{ }_{1}+\mathrm{c}_{2}{ }^{(i)}\right) t}, c_{1}^{(i)}$ and $c_{2}{ }^{(i)}$ are respectively the values of $c_{1}$ and $c_{2}$ of the ith HME. 
Table 7. NPS \&LPS of HMEs

\begin{tabular}{|c|c|c|c|}
\hline \multicolumn{2}{|c|}{ HME NPS } & LPS/km & Subareas of LPS \\
\hline$A s$ & 3 & \multicolumn{2}{|c|}{$(4.9,9.4),(13,3),(18.5,10.9)$ Industrial Area \& Traffic Area } \\
\hline$C d$ & 2 & $(6.9,13.9),(22,11.9)$ & Industrial Area \& Traffic Area \\
\hline $\mathrm{Cr}$ & 1 & $(4.9,6.4)$ & Traffic Area \\
\hline $\mathrm{Cu}$ & 1 & $(2.4,4)$ & Industrial Area \\
\hline$H g$ & 1 & $(14.5,9.5)$ & Traffic Area \\
\hline$N i$ & 1 & $(13,6)$ & Traffic Area \\
\hline$P b$ & 1 & $(3.5,1.9)$ & Traffic Area \\
\hline$Z n$ & 1 & $(14,9.5)$ & Traffic Area \\
\hline
\end{tabular}

where, NPS is short for Numbers of Pollutants Source and LPS is Location of Pollutants Source.

Analyzing the Table 6 and Table 7, we can safely draw a conclusion that Industrial Area and Traffic Area are the main location of HME pollutants source, which furtherly verify the conclusion in 3.2.

\section{Conclusion}

In this paper, based on the spatial distribution data of 8 kinds of HME given by CUMCM 2011, we first use MATLAB software to draw 2D and 3D spatial distribution figures of HMEs in the city. Then, based on the SFPI method, the evaluation model of HME pollution degree was established by using the spatial distribution data of 8 kinds of HME in the city. The pollution degree of different HME in the same and the same HME in the different subarea is graded. We analyze the results of the evaluation model and find that the Traffic Area and the Industrial Area are the most polluted areas. Besides, among 8 kinds of pollution source of HME, there are 4 kinds may be locating in the Industrial Area, 2 in the Industrial Area or Traffic Area, and the other 2 in the Living Area or Industrial Area. Therefore, we can safely draw the conclusion: HME pollution sources are all located in the Industrial Area and the Traffic Area.

Based on the results of this analysis, we will further establish a quantitative analysis model for the localization of 8 HMEs pollution sources. After that, we introduce the 2D Convection-Diffusion Equation as the basis of the pollution source location model and further modify it to meet the practical problems. Then, based on the FDM algorithm, we use the Maple software to solve the modified 2D Convection-Diffusion Equation. After solving the general solution of it, that is, the HME concentration propagation function $\varphi(x, y, t)$, we further optimize the solution to be $\varphi(x, y)$, and finally get different $\varphi_{i}(x, y)$. Finally, we can get the specific pollution sources of 8 kinds of HMEs pollutants and the corresponding subarea, finding that all the pollution sources of HMEs are all located in the industrial area or traffic area, which further verify the correctness of the previous conclusions.

About the SFPI method and 2D Convection-Diffusion Model used in this paper, we can apply them to other areas such as environmental pollution assessment, pollutant propagation model or pollution source location problem, for example, how to evaluate dust pollution degree in different districts of the city, how to determine the city air pollutant transmission path and how to research the location of pollution. By changing the relevant parameters of the model settings, we can apply this model to other related fields. Therefore, the models and methods adopted in this paper have a wide range of universality.

In the future work, we will try to further refine evaluation formula of the SFPI model and exact solution of the 2D Convection-Diffusion Equation and other issues study. Also, we will try to introduce the relevant evaluation model, such as PLI, NCI (Nemerow complex index method), further optimizing the study of related pollutant propagation models to extend to the practical problems in the research field.

\section{References}

Ahmed, B. Y. M. (1997). Climatic classification of Saudi Arabia: An application of factor--Cluster analysis. GeoJournal, 41(1), 69-84.

Alidi, A. S., \& Al-Faraj, T. N. (1994). Locating oil spill response equipment and facilities: A cluster analysis approach. GeoJournal, 34(4), 379-382.

Cheng, F., Cheng, J. P., Sang, H. C., Yu, J. L., Xi, L., \& Pi, S. S. (2013). Assessment and Correlation Analysis of Heavy Metals Pollution in Soil of Dajinshan Island. Environmental Science, 34(3), 1062-1066. http://dx.chinadoi.cn/10.13227/j.hjkx.2013.03.033 
Li, L., Wu, K. N., Zhang, L., \& Lu, Q. L. (2008). Soil Heavy Metals Pollution Assessment in the Suburb of Zhengzhou City. Chinese Journal of Soil Science, (2008.05), 1164-1168. http://dx.chinadoi.cn/10.3321/j. issn:0564-3945.2008.05.041

Lin, Y. (2009). Pollution Assessment and Prediction of Heavy Metals in soil based on Geostatistics and GIS. Central South University. http://dx.chinadoi.cn/10.7666/d.y1535697

Lin, Y. P., Zhao, Y., Hu, G. R, \& Su, G. M. (2011). The Application of Multivariate Statistical Analysis in the Source Recognition and Analysis of Heavy Metals in Pollution Soils. Earth and Environment, 39(4), 536-542.

Muller, G. (1969). Index of geoaccumulation in sediments of the Rhine River.

Qin, B. Y. (2009). The Simulation of Heavy Metal Contamination Transport in Soil Environmental System. Guangxi Normal University, 5, 13-26. http://dx.chinadoi.cn/10.7666/d.d070005

Qi, Y. H. (2006). The study on the spatial distribution and pollution assessment of heavy metal elements in soil of Tongling area based on GIS [D] (Doctoral dissertation, Hefei: Hefei University of Technology). http://dx.chinadoi.cn/10.7666/d.y870205

Sun, Y. X. (2011). Finite difference method for convection diffusion equation [D] (Doctoral dissertation, Southwest Petroleum University).

Wang, J., Liu, G. J., Fang, T., \& Yuan, Z. J.. (2013). Assessment of pollution characteristics of heavy metals in the sediments of Huaihe River(Anhui Section) by pollution load index. Journal of University of Science and Technology of China, 43(2), 97-103. http://dx.chinadoi.cn/10.3969/j.issn.0253-2778.2013.02.002

\section{Appendix A}

\section{D Spatial Distribution of Different HMEs:}

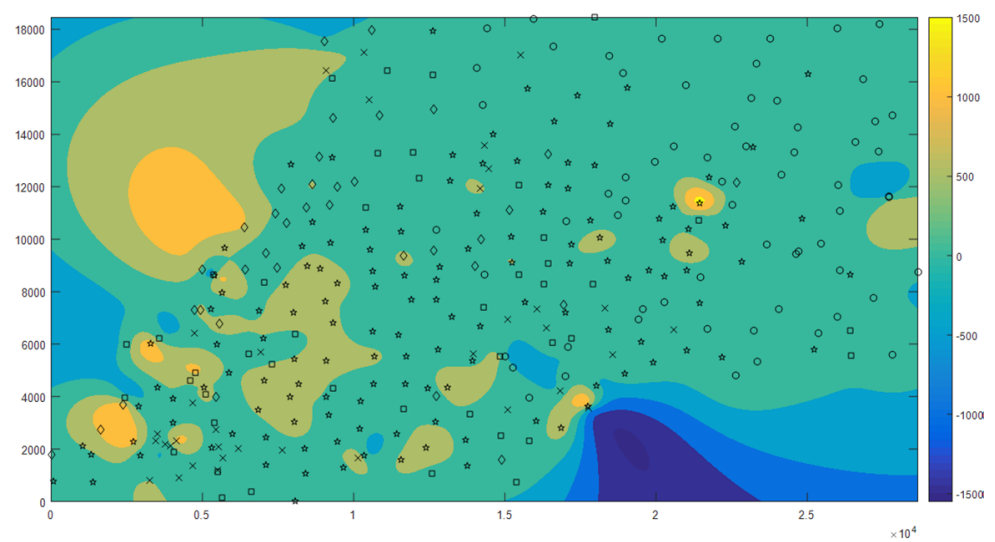

Figure A1. 2D Spatial Distribution of HME Cd

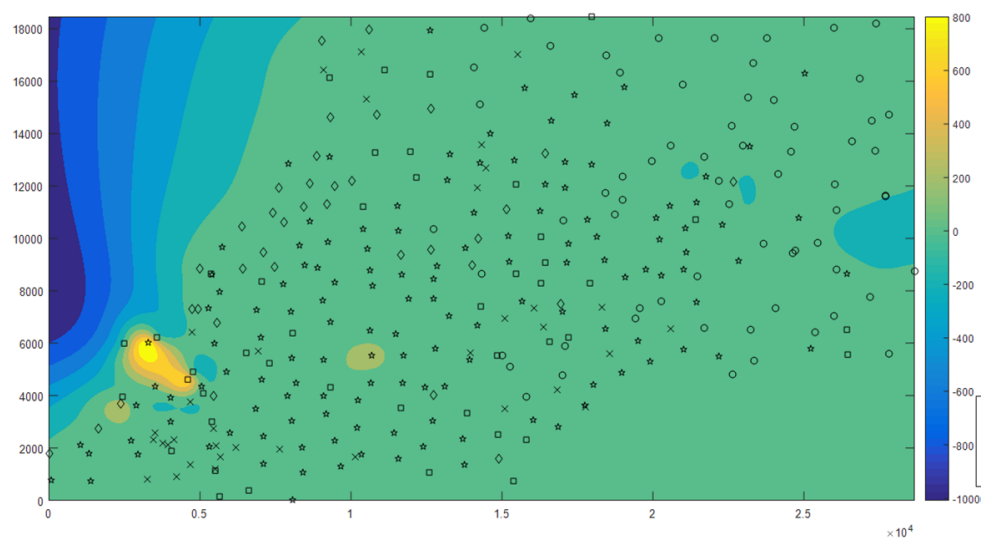

Figure A2. 2D Spatial Distribution of HME Cr 


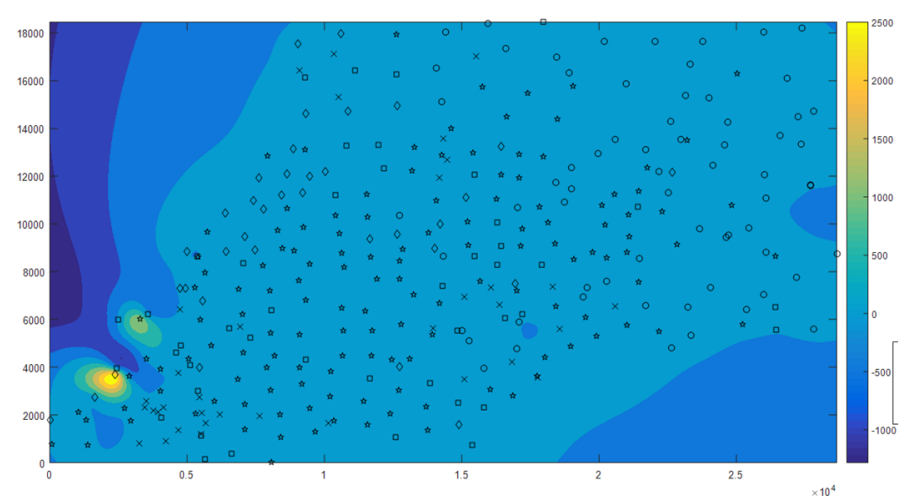

Figure A3. 2D Spatial Distribution of $\mathrm{HME} \mathrm{Cu}$

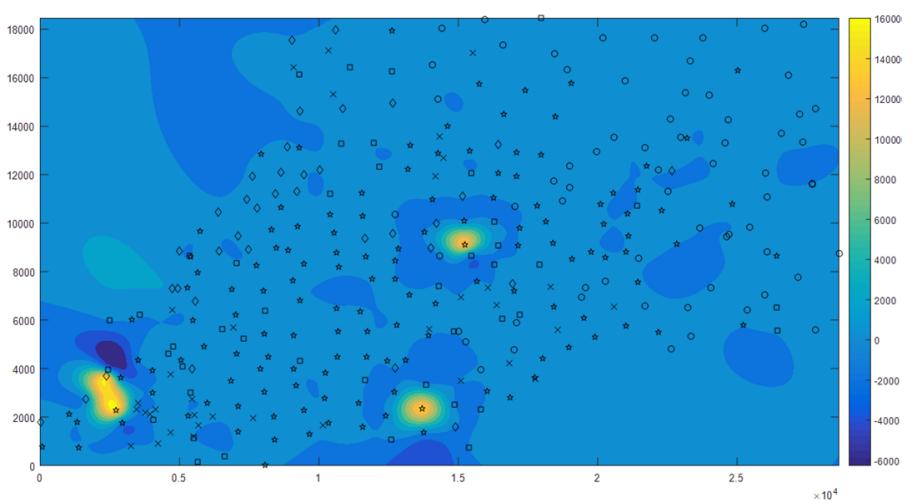

Figure A4. 2D Spatial Distribution of HME Hg

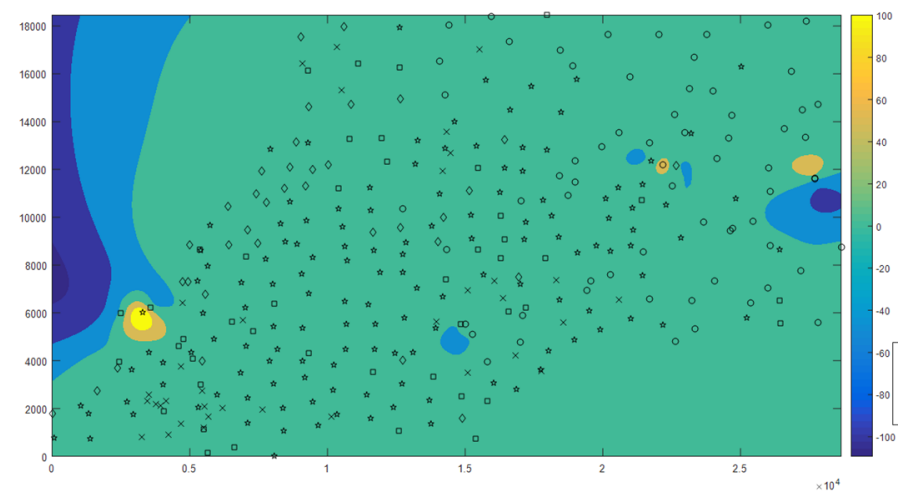

Figure A5. 2D Spatial Distribution of HME Ni

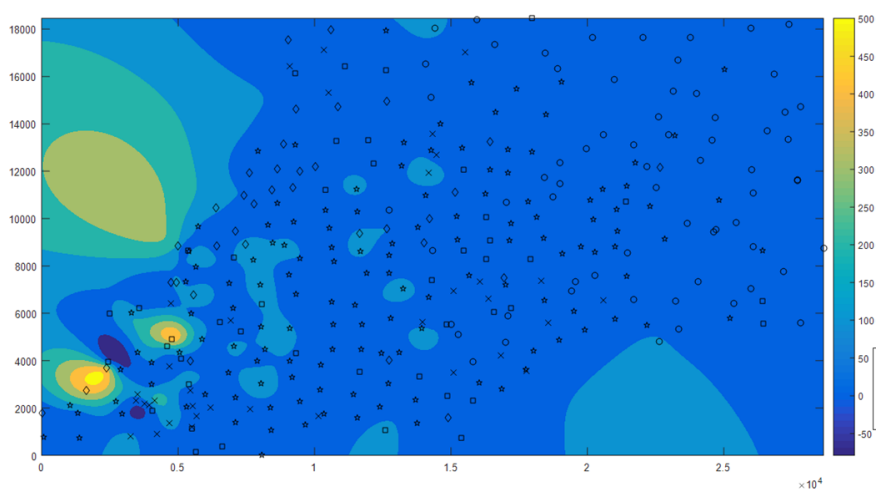

Figure A6. 2D Spatial Distribution of HME Pb 


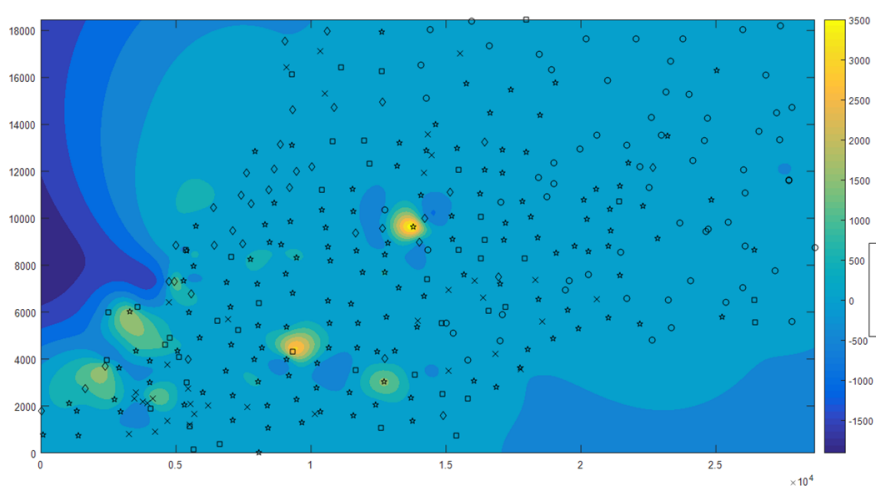

Figure A7. 2D Spatial Distribution of HME Zn

\section{Appendix B}

\section{Pollution Degree of Different Subareas:}

Table B1. Pollution Degree of Industrial Area

\begin{tabular}{|c|c|c|c|c|c|c|c|}
\hline \multirow{3}{*}{ HMEs } & \multicolumn{5}{|c|}{$P_{i}$} & \multirow{3}{*}{$\begin{array}{c}\text { Pollution } \\
\text { Rate }\end{array}$} & \multirow{3}{*}{$\begin{array}{c}\text { Pollution } \\
\text { Degree }\end{array}$} \\
\hline & $P_{i}<1$ & $1 \leq P_{i}<2$ & $2 \leq P_{i}<3$ & $3 \leq P_{i}<5$ & $P_{i} \geq 5$ & & \\
\hline & Percentage & Percentage & Percentage & Percentage & Percentage & & \\
\hline As & $13.89 \%$ & $44.44 \%$ & $33.33 \%$ & $5.56 \%$ & $2.78 \%$ & $41.67 \%$ & III \\
\hline $\mathrm{Cd}$ & $5.56 \%$ & $25.00 \%$ & $30.56 \%$ & $30.56 \%$ & $8.33 \%$ & $69.44 \%$ & IV \\
\hline $\mathrm{Cr}$ & $19.44 \%$ & $58.33 \%$ & $16.67 \%$ & $2.78 \%$ & $2.78 \%$ & $22.22 \%$ & II \\
\hline $\mathrm{Cu}$ & $2.78 \%$ & $19.44 \%$ & $25.00 \%$ & $16.67 \%$ & $36.11 \%$ & $77.78 \%$ & $\mathrm{~V}$ \\
\hline $\mathrm{Hg}$ & $13.89 \%$ & $25.00 \%$ & $11.11 \%$ & $11.11 \%$ & $41.67 \%$ & $63.89 \%$ & IV \\
\hline $\mathrm{Ni}$ & $16.67 \%$ & $58.33 \%$ & $22.22 \%$ & $2.78 \%$ & $0.00 \%$ & $25.00 \%$ & II \\
\hline $\mathrm{Pb}$ & $0.00 \%$ & $44.44 \%$ & $27.78 \%$ & $16.67 \%$ & $11.11 \%$ & $55.56 \%$ & IV \\
\hline $\mathrm{Zn}$ & $2.78 \%$ & $36.11 \%$ & $22.22 \%$ & $25.00 \%$ & $13.89 \%$ & $61.11 \%$ & IV \\
\hline
\end{tabular}

Table B2. Pollution Degree of Mountain Area

\begin{tabular}{cccccccc}
\hline \multirow{2}{*}{ HMEs } & \multicolumn{9}{c}{$P_{i}$} & Pollution & Pollution \\
& \cline { 2 - 6 } & $P_{i}<1$ & $1 \leq P_{i}<2$ & $2 \leq P_{i}<3$ & $3 \leq P_{i}<5$ & $P_{i} \geq 5$ & $\begin{array}{c}\text { Pate } \\
\text { Degree }\end{array}$ \\
\cline { 2 - 6 } & Percentage & Percentage & Percentage & Percentage & Percentage & & \\
\hline $\mathrm{As}$ & $54.55 \%$ & $36.36 \%$ & $7.58 \%$ & $1.52 \%$ & $0.00 \%$ & $9.09 \%$ & $\mathrm{I}$ \\
$\mathrm{Cd}$ & $50.00 \%$ & $39.39 \%$ & $7.58 \%$ & $3.03 \%$ & $0.00 \%$ & $10.61 \%$ & $\mathrm{I}$ \\
$\mathrm{Cr}$ & $50.00 \%$ & $36.36 \%$ & $12.12 \%$ & $0.00 \%$ & $1.52 \%$ & $13.64 \%$ & $\mathrm{I}$ \\
$\mathrm{Cu}$ & $46.97 \%$ & $42.42 \%$ & $7.58 \%$ & $0.00 \%$ & $3.03 \%$ & $10.61 \%$ & $\mathrm{I}$ \\
$\mathrm{Hg}$ & $45.45 \%$ & $46.97 \%$ & $6.06 \%$ & $0.00 \%$ & $1.52 \%$ & $7.58 \%$ & $\mathrm{I}$ \\
$\mathrm{Ni}$ & $50.00 \%$ & $37.88 \%$ & $9.09 \%$ & $1.52 \%$ & $1.52 \%$ & $12.12 \%$ & $\mathrm{I}$ \\
$\mathrm{Pb}$ & $51.52 \%$ & $43.94 \%$ & $1.52 \%$ & $3.03 \%$ & $0.00 \%$ & $4.55 \%$ & $\mathrm{I}$ \\
$\mathrm{Zn}$ & $56.06 \%$ & $42.42 \%$ & $1.52 \%$ & $0.00 \%$ & $0.00 \%$ & $1.52 \%$ & $\mathrm{I}$ \\
\hline
\end{tabular}

Table B3. Pollution Degree of Traffic Area

\begin{tabular}{|c|c|c|c|c|c|c|c|}
\hline \multirow{3}{*}{ HMEs } & \multicolumn{5}{|c|}{$P_{i}$} & \multirow{3}{*}{$\begin{array}{c}\text { Pollution } \\
\text { Rate }\end{array}$} & \multirow{3}{*}{$\begin{array}{c}\text { Pollution } \\
\text { Degree }\end{array}$} \\
\hline & $P_{i}<1$ & $1 \leq P_{i}<2$ & $2 \leq P_{i}<3$ & $3 \leq P_{j}<5$ & $P_{i} \geq 5$ & & \\
\hline & Percentage & Percentage & Percentage & Percentage & Percentage & & \\
\hline As & $16.67 \%$ & $66.67 \%$ & $14.49 \%$ & $0.72 \%$ & $1.45 \%$ & $16.67 \%$ & I \\
\hline $\mathrm{Cd}$ & $11.59 \%$ & $29.71 \%$ & $26.81 \%$ & $12.32 \%$ & $19.57 \%$ & $58.70 \%$ & IV \\
\hline $\mathrm{Cr}$ & $11.59 \%$ & $71.74 \%$ & $10.14 \%$ & $3.62 \%$ & $2.90 \%$ & $16.67 \%$ & I \\
\hline $\mathrm{Cu}$ & $1.45 \%$ & $32.61 \%$ & $14.49 \%$ & $26.09 \%$ & $25.36 \%$ & $65.94 \%$ & IV \\
\hline $\mathrm{Hg}$ & $31.88 \%$ & $26.09 \%$ & $10.14 \%$ & $13.77 \%$ & $18.12 \%$ & $42.03 \%$ & III \\
\hline $\mathrm{Ni}$ & $17.39 \%$ & $75.36 \%$ & $5.80 \%$ & $0.72 \%$ & $0.72 \%$ & $7.25 \%$ & I \\
\hline $\mathrm{Pb}$ & $12.32 \%$ & $42.75 \%$ & $26.09 \%$ & $15.94 \%$ & $2.90 \%$ & $44.93 \%$ & II \\
\hline $\mathrm{Zn}$ & $11.59 \%$ & $30.43 \%$ & $26.09 \%$ & $15.22 \%$ & $16.67 \%$ & $57.97 \%$ & IV \\
\hline
\end{tabular}


Table B4. Pollution Degree of Park Area

\begin{tabular}{cccccccc}
\hline & \multicolumn{9}{c}{$P_{i}$} & \multicolumn{2}{c}{ Pollution } & $\begin{array}{c}\text { Pollution } \\
\text { HMEs }\end{array}$ & $P_{i}<1$ & $1 \leq P_{i}<2$ & $2 \leq P_{i}<3$ & $3 \leq P_{i}<5$ & $P_{i} \geq 5$ & Rate & Degree \\
\cline { 2 - 5 } & Percentage & Percentage & Percentage & Percentage & Percentage & & \\
\hline $\mathrm{As}$ & $11.43 \%$ & $62.86 \%$ & $22.86 \%$ & $2.86 \%$ & $0.00 \%$ & $25.71 \%$ & II \\
$\mathrm{Cd}$ & $17.14 \%$ & $51.43 \%$ & $11.43 \%$ & $11.43 \%$ & $8.57 \%$ & $31.43 \%$ & III \\
$\mathrm{Cr}$ & $5.71 \%$ & $85.71 \%$ & $5.71 \%$ & $2.86 \%$ & $0.00 \%$ & $8.57 \%$ & $\mathrm{I}$ \\
$\mathrm{Cu}$ & $5.71 \%$ & $45.71 \%$ & $42.86 \%$ & $0.00 \%$ & $5.71 \%$ & $48.57 \%$ & III \\
$\mathrm{Hg}$ & $31.43 \%$ & $28.57 \%$ & $11.43 \%$ & $17.14 \%$ & $11.43 \%$ & $40.00 \%$ & III \\
$\mathrm{Ni}$ & $25.71 \%$ & $65.71 \%$ & $8.57 \%$ & $0.00 \%$ & $0.00 \%$ & $8.57 \%$ & I \\
$\mathrm{Pb}$ & $5.71 \%$ & $68.57 \%$ & $5.71 \%$ & $11.43 \%$ & $5.71 \%$ & $22.86 \%$ & II \\
$\mathrm{Zn}$ & $28.57 \%$ & $48.57 \%$ & $11.43 \%$ & $2.86 \%$ & $8.57 \%$ & $22.86 \%$ & II \\
\hline
\end{tabular}

\section{Copyrights}

Copyright for this article is retained by the author(s), with first publication rights granted to the journal.

This is an open-access article distributed under the terms and conditions of the Creative Commons Attribution license (http://creativecommons.org/licenses/by/4.0/). 